\title{
Clinical pathogenesis of typhoid fever
}

\author{
Manuela Raffatellu, R. Paul Wilson, Sebastian E. Winter, Andreas J. Bäumler \\ Department of Medical Microbiology and Immunology, School of Medicine, University of California at Davis, One Shields Ave., \\ Davis, CA 95616-8645, United States of America
}

\begin{abstract}
Human infections with Salmonella enterica results in two major groups of diseases: gastroenteritis and typhoid fever. Clinical observations suggest that gastroenteritis, caused by non-typhoidal Salmonella serovars, is characterized by a massive neutrophil influx, which keeps the infection localized to the intestinal mucosa. In contrast, the absence of neutrophilic intestinal infiltrates in the acute phase of typhoid fever suggests a propensity for typhoidal Salmonella serovars (S. Typhi, S. Paratyphi A, S. Paratyphi B and S. Paratyphi C) to evade aspects of the innate immune response and cause a systemic infection. The fact that there are no virulence genes shared by typhoidal Salmonella serovars that are absent from non-typhoidal Salmonella serovars, suggests that this innate immune evasion is mediated by different mechanisms in different typhoidal serovars. This review discusses what is known about the clinical pathogenesis of typhoid fever.
\end{abstract}

Key Words: Salmonella, Typhi, pathogenesis

J Infect Developing Countries 2008; 2(4): 260-266.

Received 6 June 2008 - Accepted 23 July 2008

Copyright (C) 2008 Raffatellu et al. This is an open access article distributed under the Creative Commons Attribution License, which permits unrestricted use, distribution, and reproduction in any medium, provided the original work is properly cited.

\section{Introduction}

Typhoid fever, one of the major bacterial infections worldwide, is caused by the humanadapted S. enterica serovar Typhi [1]. For every ten cases of $S$. Typhi infection, there are one or two cases of paratyphoid fever, caused by the human-adapted S. enterica serovars Paratyphi A, Paratyphi B and Paratyphi C [1]. Since paratyphoid fever is indistinguishable from typhoid fever in its clinical course, $S$. enterica serovars Typhi, Paratyphi A, Paratyphi B and Paratyphi C are collectively referred to as typhoidal Salmonella serovars. For unknown reasons, the frequency of infection with serovar Paratyphi $A$ is increasing in some areas of the world [2]. The highest incidence rates of typhoid fever can be found in Asia, particularly in the South-central and South-eastern regions, where an estimated 100 cases $/ 100,000$ population occur each year [1]. The improvement in sanitary conditions and health care is thought to be a key factor in reducing the incidence of typhoid fever. However, sanitation cannot explain why in Africa there is a lower incidence of typhoid fever when compared to Asia (10 cases/100,000 per year) [1].

\section{Clinical differences between typhoid fever and gastroenteritis}

Typhoid fever is transmitted by ingestion of food or water contaminated with the typhoid bacillus. This route of infection is shared with nontyphoidal Salmonella serovars (NTS), the causative agents of gastroenteritis. However, the diseases caused by these two distinct groups of bacteria are very different from a clinical perspective. While gastroenteritis caused by NTS is characterised by a rapid onset after a short incubation period (12-72h) and a brief duration (<10 days), typhoid fever has a considerably longer incubation period (median of 5 to 9 days) and longer duration of symptoms (fever persists for approximately three weeks). Also, gastroenteritis is an infection that remains localized to the intestine and mesenteric lymph nodes in immunocompetent patients, while typhoid fever is a systemic infection during which $S$. Typhi colonizes the liver, spleen and bone marrow in addition to the intestine and the mesenteric lymph nodes [3,4]. The short clinical course of gastroenteritis suggests that the onset of an adaptive immune response results in clearance of the infection. On the contrary, $S$. Typhi can persist in human tissue for long periods 
of time, indicating that the organism has a greater propensity to evade immune responses than nontyphoidal Salmonella serovars.

\section{S. Typhi overcomes the mucosal barrier in immunocompetent individuals}

NTS are unable to overcome defence mechanisms that limit bacterial dissemination from the intestinal mucosa to systemic sites of infection. However, NTS bacteraemia may occur in patients with impaired immunity $[5,6]$. Perhaps the most important group of patients that are at high risk for NTS bacteraemia are individuals affected with acquired immunodeficiency syndrome (AIDS). Because of the high prevalence of AIDS in subSaharan Africa, NTS have become a leading cause of bacteraemia [7-11]. Although AIDS patients develop NTS bacteraemia at a considerably higher frequency than healthy individuals, the frequency of typhoid fever does not differ $[12,13]$. These epidemiological observations suggest that some components of the immune response, which are defective in AIDS patients, are required to prevent systemic dissemination of NTS. In contrast, S. Typhi does not require an immunodeficient host to cause a systemic infection, as shown by its ability to cause typhoid fever in both healthy individuals and AIDS patients with similar efficiency. Thus, unlike NTS, it is likely that $S$. Typhi possesses unique virulence traits that allow it to overcome mucosal barrier functions in the immunocompetent host.

One aspect of the immune response that is important to control infection with NTS but not with S. Typhi is the interleukin (IL)-12/interferon (IFN)$\gamma$ axis. Mutations in genes that encode components of the IL-12/IFN- $\gamma$ axis increase patients' susceptibility to infections with NTS, but not to infections with $S$. Typhi $[14,15]$. In agreement with these clinical observations, a recent study showed that polymorphisms in IFNG, $I L-12 B$ and IFNGR1 do not appear to contribute to increased susceptibility to typhoid fever [16]. A possible explanation for this observation is that $S$. Typhi (but not NTS) may possess virulence mechanisms that allow it to evade the TLRdependent IL-12/IFN- $\gamma$ axis. The IL-12/IFN- $\gamma$ axis is a major immunoregulatory system that bridges innate and adaptive immunity and is induced by stimulation of Toll-like receptors (TLRs) in macrophages and dendritic cells [17]. IL-12 and
IFN- $\gamma$ are important for the control of $S$. Typhimurium infection in mice [18-20] and evasion of the IL-12/IFN- $\gamma$ axis by $S$. Typhi may help explain its greater propensity to evade immune responses encountered in tissue.

\section{NTS trigger a stereotypical host response that results in inflammatory diarrhoea}

An important difference between typhoid fever and gastroenteritis is the host response elicited in the intestinal mucosa. Gastroenteritis caused by NTS is a typical diarrhoeal disease characterised by exudative inflammation, with neutrophil recruitment in the terminal ileum and colon and the predominance of neutrophils in stool samples of patients [21-23]. Invasion of the intestinal mucosa by NTS is detected by the innate immune system of the host, which responds by recruiting neutrophils to the site of infection [24]. The innate immune system can distinguish between self and microbial intruders by recognizing molecular patterns exclusively found in microorganisms through pathogen recognition receptors (PRRs), including the membrane localized TLRs and the cytosolic Nod-like receptors (NLRs). Expression of PRRs at the basolateral (but not the apical) pole of intestinal epithelial cells and on cells in the lamina propria (e.g. macrophages and dendritic cells) enable the innate immune system to distinguish lumenal from invasive microbes. This allows for an appropriate response to invasive enteric pathogens, such as NTS, by triggering exudative inflammation [25, 26]. Because a small number of PRRs triggers the bulk of transcriptional changes through activation of the transcription factors NF$\kappa B, A P-1$ and IRF3 in response to bacterial invasion, this host response is not specific to a pathogen but rather to a group of enteroinvasive organisms, including Shigella spp., Campylobacter spp. and NTS [21-23]. The resulting neutrophil influx and inflammatory diarrhoea are a stereotypic host response to bacterial invasion of the intestinal mucosa [27].

\section{Clinical data suggest that S. Typhi may evade innate immune responses}

In contrast to gastroenteritis, typhoid fever is not a typical diarrhoeal disease and the intestinal pathology is characterised by interstitial inflammation with predominantly mononuclear infiltrates, while neutrophils are scarce [23, 28-31]. 
Diarrhoea, which may occur after the onset of fever in approximately one third of typhoid fever patients, is associated with faecal leukocyte populations that are dominated by mononuclear cells $[23,32,33]$. The fact that typhoid fever is a very invasive infection raises the question why penetration of the human intestinal mucosa by $S$. Typhi does not trigger the stereotypic host response (i.e. neutrophil influx) that is typically observed during infection with other enteroinvasive pathogens. Several tissue culture studies support the concept that $S$. Typhi infection results in reduced inflammatory responses when compared to NTS, such as S. Typhimurium. Gene expression analysis in intestinal epithelial cells shows that unlike $S$. Typhimurium, $S$. Typhi does not trigger a pro-inflammatory response through TLR5 stimulation [34]. Also, while S. Typhimurium triggers neutrophil transmigration across a monolayer of polarized colonic epithelial cells, $S$. Typhi does not [35]. Furthermore, infection of macrophage-like cells with $S$. Typhi results in markedly reduced production of the neutrophil chemoattractant interleukin (IL)-8 compared to infection with S. Typhimurium [36]. Collectively, these observations raise the possibility that $S$. Typhi expresses virulence mechanisms allowing it to down-regulate a PRR-mediated host response in the intestinal mucosa that results in the absence of neutrophil infiltration and inflammatory diarrhoea.

The hypothesis that $S$. Typhi can evade PRRmediated host responses is consistent with two additional clinical observations. First, pyrogenic cytokines, like tumor necrosis factor (TNF)- $\alpha$ and IL-1 $\beta$, are elevated in sera of typhoid fever patients compared to healthy individuals $[37,38]$ but to a lesser extent than in sera of patients with sepsis [39-41]. Also, higher concentrations of bacteria in the blood would predict a more severe prognosis in patients with Gram-negative sepsis but not in typhoid fever patients [42-45]. An attenuation of PRR-mediated host responses may be one of the reasons septic shock appears not to contribute to mortality during typhoid fever. Although polymorphisms in the tumor necrosis factor alpha promoter region (TNFA-308) were found to be associated either with increased susceptibility to typhoid fever or with its severity $[46,47]$, most polymorphisms in pro-inflammatory genes (TNFA238, ILIA, IL1B, TNFRSF1A, CASP1 and CRP) do not seem to contribute to increased susceptibility to typhoid fever [16]. These epidemiological findings seem to provide support for clinical observations that septic shock does not occur in typhoid fever patients because $S$. Typhi does not trigger a strong pro-inflammatory response through PRR signalling.

The second clinical observation is the following: patients with chronic granulomatous disease (CGD), a primary immunodeficiency preventing the generation of phagocyte oxidative burst, are more susceptible to infection with NTS and frequently develop bacteraemia [48]. However, there is no positive correlation between the frequency or severity of typhoid fever and CGD. The induction of an oxidative burst in professional phagocytes depends on TLR signalling, since activation of NADPH oxidase by MAP kinases depends on the TLR adaptor protein MyD88 [49, 50]. During a systemic bacterial infection, leukocytes generally produce more reactive oxygen intermediates, as indicated by an increased ability to reduce nitroblue tetrazoleum (NBT). Based on this observation, it has been proposed that an NBT blood test can be used clinically to differentiate bacterial sepsis from other fevers (i.e. from local enteric diseases, viral infection, plasmodium infection or fever not caused by an infectious agent) [51]. Interestingly, this study found that typhoid fever (but not bacteraemia with NTS) is associated with a false negative NBT blood test, indicating a markedly reduced oxidative response in blood of patients infected with S. Typhi [51]. Moreover, neutrophils isolated from human volunteers exhibit low oxygen consumption when infected with virulent $S$. Typhi expressing a capsule $[52,53]$. These data show that one TLRdependent host response evaded by $S$. Typhi is the generation of an oxidative burst during interaction with phagocytes. The above review of clinical observations suggests that many differences between typhoid fever and gastroenteritis may be explained by assuming that $S$. Typhi modulates aspects of the innate immune response.

Relatively few studies directly investigate the pathogenesis of typhoid fever, but instead use a surrogate host (i.e. mice instead of humans) and a surrogate pathogen (i.e. S. Typhimurium instead of $S$. Typhi) to model the infection. This approach has been highly successful in identifying and 
characterizing some major virulence mechanisms common to enteric fever and NTS. However, an important limitation of this approach is that NTS cause a typhoid-like disease solely in the mouse, but not in humans, where they cause a localized gastroenteritis. Thus, enteric fever serovars must possess virulence mechanisms that are absent from NTS and are responsible for the ability to cause typhoid or paratyphoid fever in humans. Interestingly, virulence traits that contribute to the host response are common to all NTS serovars. These include (i) the type three secretion system encoded on pathogenicity island 1 (T3SS-1), which mediates invasion of the intestinal epithelium; (ii) the type three secretion system encoded on pathogenicity island 2 (T3SS-2), which is required for survival within macrophages; (iii) expression of strong agonists of innate pattern recognition receptors (LPS and flagellin), which are important for triggering a TLR-mediated inflammatory response. These observations suggest that $S$. Typhi must have acquired additional factors that further modulate the host response during infection. For example, a reduction of TLRmediated responses by $S$. Typhi could help explain the scarcity of neutrophils in intestinal infiltrates, the relatively low levels of $T N F-\alpha$ during bacteraemia, and the inhibition of an oxidative burst in phagocytes. Reduction of TLR signalling may interfere with the induction of the IL-12/IFN- $\gamma$ axis, which may be one of the mechanisms by which S. Typhi evades adaptive immunity and persists in the host.

\section{The viaB locus enables $S$. Typhi to evade recognition through TLR4 and TLR5}

One of the virulence determinants that allows $S$. Typhi to modulate host responses during infection is the viaB locus encoded on Salmonella Pathogenicity Island 7 (SPI7) $[36,54,55]$, which is the largest of the genomic regions present in $S$. Typhi but absent in S. Typhimurium [56]. The presence of the viaB locus allows $S$. Typhi to reduce the production of IL-8 in intestinal epithelial cells, TNF- $\alpha$ in macrophages and neutrophil recruitment into the intestinal mucosa in vivo [36, 54, 55, 57-59]. This DNA locus contains genes involved in the regulation (tviA), biosynthesis (tviBCDE) and export (vexABCDE) of S. Typhi's Virulence (Vi) capsule [60]. Recent analysis of the $v i a B$ locus has begun to shed light on the mechanisms by which $S$. Typhi evades aspects of the innate immune surveillance system.

IL-8 production in intestinal epithelial cells can be induced by bacterial flagellin, which stimulates TLR5, a pathogen recognition receptor expressed basolaterally on polarized monolayers [26]. The regulator TviA, which is the activator of the biosynthesis genes of the viaB operon, is a repressor of genes outside the viaB locus, including the T3SS-1 and the flagella regulon [54, 61]. In vitro studies show that under conditions of high osmolarity, expression of TviA, and therefore of the Vi capsule, are repressed, while the T3SS-1 and flagella are expressed [61]. Under conditions of low osmolarity, TviA is expressed, resulting in expression of the $\mathrm{Vi}$ capsule and repression of the T3SS-1 as well as the flagella regulon [61]. Because a high osmolarity environment mimics the intestinal lumen, and low osmolarity environment mimics the salt concentration in blood or tissue, a plausible explanation is that $S$. Typhi expresses flagella and T3SS-1 in the intestinal lumen, to achieve maximal colonization. However, once in the lamina propria, $S$. Typhi activates expression of the viaB locus (including the regulator TviA) and down-regulates flagella expression to avoid TLR recognition. TviA represses expression and secretion of FliC, the ligand for TLR5, which results in reduced IL-8 secretion by intestinal epithelial cells [54]. Furthermore, introduction of the tviA gene into $S$. Typhimurium results in repression of flagellin secretion and IL-8 expression in epithelial cells [54]. Thus, TviAmediated repression of flagellin explains the low propensity of S. Typhi to elicit IL-8 expression in intestinal epithelial cells [34].

Recognition of LPS by TLR4 expressed on macrophages and monocytes during bacteraemia is an important source of cytokine production, most importantly TNF- $\alpha$. Purified S. Typhi LPS is a potent TLR4 agonist, thus raising the question why bacteraemia during typhoid fever is associated with only moderately increased levels of TNF- $\alpha$. A role of the Vi capsule in evading TLR4 signalling became evident by comparison of TNF- $\alpha$ production in the sepsis mouse model after infection with either $S$. Typhimurium wild-type or an $S$. Typhimurium strain carrying the viaB operon [55]. The capsulated strain elicited less TNF- $\alpha$ expression in the liver than the non-capsulated strain in wild-type mice, while no difference in 
TNF- $\alpha$ expression elicited by both strains was observed in TLR4 ${ }^{-1-}$ mice. Thus, expression of the $\mathrm{Vi}$ capsular antigen is required for evading TLR4 dependent responses, suggesting that the $\mathrm{Vi}$ capsule is able to mask S. Typhi's LPS [55].

\section{Conclusions}

The picture emerging from these studies is that the viaB-locus allows $S$. Typhi to modulate host responses by evading innate immune surveillance through TLR5 and TLR4. These recent insights into typhoid fever pathogenesis suggest a possible mechanism for numerous clinical observations that hint at the ability of $S$. Typhi to evade aspects of the innate immune system. The fact that $S$. Typhi, S. Paratyphi A, S. Paratyphi B and S. Paratyphi C do not share virulence genes that are absent from non-typhoidal Salmonella serovars suggests that innate immune evasion is mediated by different mechanisms by these pathogens. Additional research is needed to identify these virulence mechanisms in typhoidal Salmonella serovars lacking the viaB region.

\section{Acknowledgements}

Work in A.J.B. lab was supported by Public Health Service grants Al040124, Al044170 and Al079173.

\section{References}

1. Crump JA, Luby SP, Mintz ED (2004) The global burden of typhoid fever. Bull World Health Organ 82:346-353.

2. Ochiai RL, Wang $X$, von Seidlein L, Yang J, Bhutta ZA, Bhattacharya SK, Agtini M, Deen JL, Wain J, Kim DR, Ali M, Acosta CJ, Jodar L, Clemens JD (2005) Salmonella paratyphi A rates, Asia. Emerg Infect Dis 11:1764-1766.

3. Tsolis RM, Kingsley RA, Townsend SM, Ficht TA, Adams LG, Bäumler AJ (1999) Of mice, calves, and men. Comparison of the mouse typhoid model with other Salmonella infections. Adv Exp Med Biol 473:261-274.

4. Santos RL, Zhang S, Tsolis RM, Kingsley RA, Adams LG, Bäumler AJ (2001) Animal Models of Salmonella Infections: Enteritis vs. Typhoid Fever. Mircrob Infect 3:1335-1344.

5. Mandal BK, Brennand J (1988) Bacteraemia in salmonellosis: a 15 year retrospective study from a regional infectious diseases unit. Bmj 297:1242-1243.

6. Diez Dorado R, Tagarro Garcia A, Baquero-Artigao F, Garcia-Miguel MJ, Uria Gonzalez MJ, Pena Garcia P, del Castillo Martin F (2004) Non-typhi Salmonella bacteremia in children: an 11-year review. An Pediatr (Barc) 60:344348.

7. Kassa-Kelembho E, Mbolidi CD, Service YB, Morvan J, Minssart P (2003) Bacteremia in adults admitted to the Department of Medicine of Bangui Community Hospital (Central African Republic). Acta Trop 89:67-72.

8. Nathoo KJ, Chigonde S, Nhembe M, Ali MH, Mason PR (1996) Community-acquired bacteremia in human immunodeficiency virus-infected children in Harare, Zimbabwe. Pediatr Infect Dis J 15:1092-1097.

9. Gordon MA, Walsh AL, Chaponda M, Soko D, Mbvwinji M, Molyneux ME, Gordon SB (2001) Bacteraemia and mortality among adult medical admissions in Malawi-predominance of non-typhi salmonellae and Streptococcus pneumoniae. J Infect 42:44-49.

10. Kankwatira AM, Mwafulirwa GA, Gordon MA (2004) Nontyphoidal salmonella bacteraemia--an under-recognized feature of AIDS in African adults. Trop Doct 34:198-200.

11. Molyneux E (2004) Bacterial infections in children with HIVIAIDS. Trop Doct. 34:195-198.

12. Seydi M, Soumare M, Sow AI, Diop BM, Sow PS (2005) Current aspects of Salmonella bacteremia cases in the Ibrahima Diop Mar Infectious Diseases clinic, Fann National Hospital Center (Senegal). Med Mal Infect 35:23-27.

13. Pithie AD, Malin AS, Robertson VJ, (1993) Salmonella and Shigella bacteraemia in Zimbabwe. Cent Afr J Med 39:110-112.

14. Lammas DA, De Heer E, Edgar JD, Novelli V, A BenSmith,Baretto R, Drysdale P, Binch J, MacLennan C, Kumararatne DS, Panchalingam S, Ottenhoff $\mathrm{TH}$, Casanova JL, Emile JF (2002) Heterogeneity in the granulomatous response to mycobacterial infection in patients with defined genetic mutations in the interleukin 12-dependent interferon-gamma production pathway. Int $\mathrm{J}$ Exp Pathol 83:1-20.

15. MacLennan C, Fieschi C, Lammas DA, Picard C, Dorman SE, Sanal O, MacLennan JM, Holland SM, Ottenhoff TH, Casanova JL, Kumararatne DS (2004) Interleukin (IL)-12 and IL-23 are key cytokines for immunity against Salmonella in humans. J Infect Dis 190:1755-1757.

16. Ali S, Vollaard AM, Kremer D, de Visser AW, Martina CA, Widjaja S, Surjadi C, Slagboom E, van de Vosse E, van Dissel JT (2007) Polymorphisms in proinflammatory genes and susceptibility to typhoid fever and paratyphoid fever. J Interferon Cytokine Res 27:271-279.

17. Schuetze N, Schoeneberger S, Mueller U, Freudenberg MA, Alber G, Straubinger RK (2005) IL-12 family members: differential kinetics of their TLR4-mediated induction by Salmonella Enteritidis and the impact of IL10 in bone marrow-derived macrophages. Int Immunol 17:649-659.

18. Mastroeni P, Harrison JA, Chabalgoity JA, Hormaeche CE (1996) Effect of interleukin 12 neutralization on host resistance and gamma interferon production in mouse typhoid. Infect Immun 64:189-196.

19. Bao S, Beagley KW, France MP, Shen J, Husband AJ (2000) Interferon-gamma plays a critical role in intestinal immunity against Salmonella typhimurium infection. Immunology 99:464-472.

20. Nauciel C, Espinasse-Maes F (1992) Role of gamma interferon and tumor necrosis factor alpha in resistance to Salmonella typhimurium infection. Infect Immun 60:450454.

21. McGovern VJ, Slavutin LJ (1979) Pathology of salmonella colitis. Am J Surg Pathol 3:83-90.

22. Day DW, Mandal BK, Morson BC (1978) The rectal biopsy appearances in Salmonella colitis. Histopathology 2:117-131. 
23. Harris JC, Dupont HL, Hornick RB (1972) Fecal leukocytes in diarrheal illness. Ann Intern Med 76:697703.

24. Tukel C, Raffatellu M, Chessa D, Wilson RP, Akcelik M, Bäumler AJ (2006) Neutrophil influx during non-typhoidal salmonellosis: who is in the driver's seat? FEMS Immunol Med Microbiol 46:320-329.

25. Abreu MT, Thomas LS, Arnold ET, Lukasek K, Michelsen KS, Arditi M (2003) TLR signaling at the intestinal epithelial interface. J Endotoxin Res 9:322-330.

26. Gewirtz AT, Navas TA, Lyons S, Godowski PJ, Madara JL (2001) Cutting edge: bacterial flagellin activates basolaterally expressed TLR5 to induce epithelial proinflammatory gene expression. J Immunol 167:18821885.

27. Raffatellu M, Chessa D, Wilson RP, Tukel C, Akcelik M, Bäumler AJ (2006) Capsule-mediated immune evasion: a new hypothesis explaining aspects of typhoid fever pathogenesis. Infect Immun 74:19-27.

28. Kraus MD, Amatya B, Kimula Y (1999) Histopathology of typhoid enteritis: morphologic and immunophenotypic findings. Mod Pathol 12:949-955.

29. Sprinz $H$, Gangarosa EJ, Williams $M$, Hornick RB, Woodward TE (1966) Histopathology of the upper small intestines in typhoid fever. Biopsy study of experimental disease in man. Am J Dig Dis 11:615-624.

30. Mukawi TJ (1978) Histopathological study of typhoid perforation of the small intestines. Southeast Asian $\mathrm{J}$ Trop Med Public Health. 9:252-255.

31. Nguyen QC, Everest $P$, Tran TK, House D, Murch $S$, Parry C, Connerton P, Phan VB, To SD, Mastroeni P, White NJ, Tran TH, Vo VH, Dougan G, Farrar JJ, J Wain (2004) A clinical, microbiological, and pathological study of intestinal perforation associated with typhoid fever. Clin Infect Dis 39:61-67.

32. Guyot J, Gonvers JJ, Pyndiah N, Heitz M (1984) Value of fecal leukocyte studies in cases of acute diarrhea. Schweiz Med Wochenschr 114:634-636.

33. Alvarado T (1983) Faecal leucocytes in patients with infectious diarrhoea. Trans R Soc Trop Med Hyg. 77:316320.

34. Zeng $\mathrm{H}$, Carlson $A Q$, Guo $Y, Y u ~ Y$, Collier-Hyams LS, Madara JL, Gewirtz AT, Neish AS (2003) Flagellin is the major proinflammatory determinant of enteropathogenic Salmonella. J Immunol 171:3668-3674.

35. McCormick BA, Miller SI, Carnes D, Madara JL (1995) Transepithelial signaling to neutrophils by salmonellae: a novel virulence mechanism for gastroenteritis. Infect Immun 63:2302-2309.

36. Raffatellu M, Chessa D, Wilson RP, Dusold R, Rubino S, Bäumler AJ (2005) The Vi capsular antigen of Salmonella enterica serotype Typhi reduces Toll-like receptordependent interleukin-8 expression in the intestinal mucosa. Infect Immun 73:3367-3374.

37. Butler T, Ho M, Acharya G, Tiwari M, Gallati H (1993) Interleukin-6, gamma interferon, and tumor necrosis factor receptors in typhoid fever related to outcome of antimicrobial therapy. Antimicrob Agents Chemother $37: 2418-2421$.

38. Keuter M, Dharmana E, Gasem MH, van der VenJongekrijg J, Djokomoeljanto R, Dolmans WM, Demacker P, Sauerwein R, Gallati H, van der Meer JW (1994)
Patterns of proinflammatory cytokines and inhibitors during typhoid fever. J Infect Dis 169:1306-1311.

39. Waage A, Brandtzaeg $P$, Halstensen A, Kierulf $P, T$ Espevik (1989) The complex pattern of cytokines in serum from patients with meningococcal septic shock. Association between interleukin 6, interleukin 1, and fatal outcome. J Exp Med 169:333-338.

40. Wortel $\mathrm{CH}$, von der Mohlen MA, van Deventer SJ, Sprung $\mathrm{CL}$, Jastremski M, Lubbers MJ, Smith CR, Allen IE, ten Cate JW (1992) Effectiveness of a human monoclonal anti-endotoxin antibody (HA-1A) in gram-negative sepsis: relationship to endotoxin and cytokine levels. J Infect Dis 166:1367-1374.

41. Girardin E, Grau GE, Dayer JM, Roux-Lombard P, Lambert PH (1988) Tumor necrosis factor and interleukin1 in the serum of children with severe infectious purpura. N Engl J Med 319:397-400.

42. DuPont HL, Spink WW (1969) Infections due to gramnegative organisms: an analysis of 860 patients with bacteremia at the University of Minnesota Medical Center, 1958-1966. Medicine (Baltimore). 48:307-332.

43. Dietzman DE, Fischer GW, Schoenknecht FD (1974) Neonatal Escherichia coli septicemia--bacterial counts in blood. J Pediatr 85:128-130.

44. Butler T, Levin J, Linh NN, Chau DM, Adickman M, Arnold K (1976) Yersinia pestis infection in Vietnam. II. Quantiative blood cultures and detection of endotoxin in the cerebrospinal fluid of patients with meningitis. J Infect Dis 133:493-499.

45. Butler T, Bell WR, Levin J, Linh NN, Arnold K (1978) Typhoid fever. Studies of blood coagulation, bacteremia, and endotoxemia. Arch Intern Med 138:407-410.

46. Dunstan SJ, Nguyen $\mathrm{TH}$, Rockett $\mathrm{K}$, Forton J, Morris AP, Diakite M, Mai NL, Le TP, House D, Parry CM, Ha V, Dougan G, Tran TH, Kwiatowski D, Farrar JJ (2007) A TNF region haplotype offers protection from typhoid fever in Vietnamese patients. Hum Genet 122:51-61.

47. Dunstan SJ, Stephens HA, Blackwell JM, Duc CM, Lanh MN, Dudbridge F, Phuong CX, Luxemburger C, Wain J, Ho VA, Hien TT, Farrar J, Dougan G (2001) Genes of the class II and class III major histocompatibility complex are associated with typhoid fever in Vietnam. J Infect Dis 183:261-268.

48. Winkelstein JA, Marino MC, Johnston RBJr, Boyle J, Curnutte J, Gallin JI, Malech HL, Holland SM, Ochs H, Quie P, Buckley RH, Foster CB, Chanock SJ, Dickler H (2000) Chronic granulomatous disease. Report on a national registry of 368 patients. Medicine (Baltimore) 79:155-169.

49. Laroux FS, Romero $X$, Wetzler L, Engel $P$, Terhorst $C$ (2005) Cutting edge: MyD88 controls phagocyte NADPH oxidase function and killing of gram-negative bacteria. J Immunol 175:5596-5600.

50. Rosenberger CM, Finlay BB (2002) Macrophages inhibit Salmonella typhimurium replication through MEK/ERK kinase and phagocyte NADPH oxidase activities. J Biol Chem 277:18753-18762.

51. Miller RM, Garbus J, Schwartz AR, DuPont HL, Levine MM, Clyde DF, Hornick RB (1976) A modified leukocyte nitroblue tetrazolium test in acute bacterial infection. Am J Clin Pathol 66:905-910.

52. Kossack RE, Guerrant RL,Densen $P$, Schadelin J, Mandell GL (1981) Diminished neutrophil metabolism 
after phagocytosis of virulent Salmonella typhi. Infect Immun 31:674-678.

53. Miller RM, Garbus J, Hornick RB (1972) Lack of enhanced oxygen consumption by polymorphonuclear leucocytes on phagocytosis of virulent Salmonella typhi. Science 175:1010-1011.

54. Winter, SE, Raffatellu $M$, Wilson RP, Russmann $H$, Bäumler AJ (2008) The Salmonella enterica serotype Typhi regulator TviA reduces interleukin-8 production in intestinal epithelial cells by repressing flagellin secretion. Cell Microbiol 10:247-261.

55. Wilson RP, Raffatellu M, Chessa D, Winter SE, Tukel C Bäumler AJ (2008) The Vi-capsule prevents Toll-like receptor 4 recognition of Salmonella. Cell Microbiol 10:876-890.

56. Parkhill J, Dougan G, James KD, Thomson NR, Pickard D, Wain J, Churcher C, Mungall KL, Bentley SD, Holden MT, Sebaihia M, Baker S, Basham D, Brooks K, Chillingworth T, Connerton P, Cronin A, Davis P, Davies RM, Dowd L, White N, Farrar J, Feltwell T, Hamlin N, Haque A, Hien TT, Holroyd S, Jagels K, Krogh A, Larsen TS, Leather S, Moule S, O'Gaora P, Parry C, Quail M, Rutherford K, Simmonds M, Skelton J, Stevens K, Whitehead S, Barrell BG (2001) Complete genome sequence of a multiple drug resistant Salmonella enterica serovar Typhi CT18. Nature 413:848-852.

57. Hirose K, Ezaki T, Miyake M, Li T, Khan AQ, Kawamura Y, Yokoyama H, and Takami T (1997) Survival of Vicapsulated and Vi-deleted Salmonella typhi strains in cultured macrophage expressing different levels of CD14 antigen. FEMS Microbiol Lett 147:259-265.

58. Sharma A, Qadri A (2004) Vi polysaccharide of Salmonella typhi targets the prohibitin family of molecules in intestinal epithelial cells and suppresses early inflammatory responses. Proc Natl Acad Sci U S A 101:17492-17497.

59. Raffatellu M, Santos RL, Chessa D, Wilson RP, Winter SE, Rossetti CA, Lawhon SD, Chu H, Lau T, Bevins CL, Adams LG, Bäumler AJ (2007) The capsule encoding the viaB locus reduces interleukin-17 expression and mucosal innate responses in the bovine intestinal mucosa during infection with Salmonella enterica serotype Typhi. Infect Immun 75:4342-4350.

60. Kolyva S, Waxin H, Popoff MY (1992) The Vi antigen of Salmonella typhi: molecular analysis of the viaB locus. J Gen Microbiol 138:297-304.

61. Arricau N, Hermant D, Waxin H, Ecobichon C, Duffey PS, Popoff MY (1998) The RcsB-RcsC regulatory system of Salmonella typhi differentially modulates the expression of invasion proteins, flagellin and $\mathrm{Vi}$ antigen in response to osmolarity. Mol Microbiol 29:835-850.

Corresponding Author: Andreas J. Bäumler, Department of Medical Microbiology and Immunology, School of Medicine, University of California at Davis, One Shields Ave., Davis, CA 95616-8645, USA, E-mail: ajbaumler@ucdavis.edu

Conflict of interest: No conflict of interest is declared. 